\title{
Introducing New Perspectives in the Use of Social Technologies in Learning: Social Constructionism
}

\author{
Antigoni Parmaxi ${ }^{1}$, Panayiotis Zaphiris ${ }^{1}$, Eleni Michailidou ${ }^{1}$, \\ Salomi Papadima-Sophocleous ${ }^{2}$, and Andri Ioannou ${ }^{1}$ \\ ${ }^{1}$ Department of Multimedia and Graphic Arts, \\ Cyprus University of Technology, Lemesos, Cyprus \\ ${ }^{2}$ Language Centre, Cyprus University of Technology, Lemesos, Cyprus \\ \{antigoni.parmaxi, panayiotis.zaphiris, eleni.michailidou, \\ salomi.sophocleous, andri.i.ioannou\}@cut.ac.cy
}

\begin{abstract}
This paper reports on a qualitative study of the use of social technologies, explored in the context of an intensive 650-hour Greek language course. Qualitative content analysis of instructors' field notes, students' and instructors' reflections, interviews and a focus group was employed aiming at identifying the use of social technologies as a platform for constructing an online artifact. To triangulate the findings, the study also collected data by observing students' activity with social technologies. A code scheme was developed which manifests the use of social technologies as a social constructionism platform identifying its major dimensions: exploration of ideas, construction of online artifact and evaluation of the constructed artifact. Actions within each dimension that indicate the manifestation of social constructionism are identified and discussed. This study revealed results in favor of the use of social technologies as social constructing platforms suggesting a new framework for their use.
\end{abstract}

Keywords: social technologies, web 2.0 technologies, social constructionism, online artifact.

\section{Introduction}

The emergence of social technologies transformed the way we communicate, learn and interact with others. Among other tools, social or Web 2.0 technologies received substantial consideration from instructional designers, researchers and practitioners. Each stakeholder explores these technologies from different angles aiming at describing and explicating how these technologies are used, by whom and for what purpose.

The potentials of these technologies have also expanded the possibilities of teaching and learning and several projects have evolved which exploit blogs and wikis as social writing platforms. As [2] points out, "social writing platforms appear to be logistically useful tools for a variety of campus needs, from student group learning to faculty department work to staff collaborations". However, the potentials of these technologies are not limited to this framework. This study aspires to widen the applicability of these technologies drawing on the theoretical framework of 
constructionism [21-23]. The essence of constructionism can be summarized in its conviction that individual learning occurs more effectively when learners understand the world around them by making tangible objects. Thus, the main aim of this study is to explore the potential that social technologies offer in facilitating teams of learners in order to socially construct an online artifact.

\section{Objectives and Related Work}

\subsection{Objectives}

Social technologies have been widely researched, however little work has been done on their use as social constructing platforms. In this study, we exploit this possibility by providing insight to the use of social technologies in a longitudinal Greek as a second language (L2) course. The aim of this study is broken down in the following objectives:

1. Explore the potential that social technologies offer in facilitating teams of learners in order to socially construct an online artifact

2. Develop a code scheme that captures the core dimensions of social technologies as social constructing platforms

3. Explore the role(s) adopted by students and instructor within a social constructing environment

In the sections that follow an overview of the relevant literature is provided related to Computer Assisted Language Learning, Social Technologies in CALL and Papert's theoretical framework.

\subsection{Computer Assisted Language Learning (CALL)}

Gamper and Knapp [7] define Computer Assisted Language Learning as "a research field which explores the use of computational methods and techniques as well as new media for language learning and teaching". The popularity of the field of CALL has increased incrementally, especially with the advent of recent technological developments.

The question of CALL effectiveness is brought forward repeatedly in CALL research [1], [9], [12], [34-35], [37], [39]. However, this is not a simple yes or no question as often other parameters need to be considered. Zhao [39] in his literature review and meta-analysis for assessing the potential of technology for improving language education, showed that the use of technology in language learning is at least as effective as teacher-delivered instruction. However, he points out that these findings should be interpreted with caution due to the limited number of studies that provided satisfactory data for his meta-analysis; journals' tendency to publish studies with positive gains; the fairly small samples and rare employment of random sampling in the studies and the fact that all of them were carried out with college students and adult learners. Moreover, in most cases teachers were implementing the technology use, thus adventuring the possibility of the "Pygmalion effect". Zhao [39] also exploits four issues that need to be addressed in order for information and communication technologies to significantly improve language learning. First, curricula and 
course content needs to be developed with an eye to include a wide range of available technologies that drive pedagogical solutions. Second, further research needs to be conducted in order to exploit effective ways of technology use. Third, since technology use and research has not expanded to K-12 classrooms, technology needs to be promoted and research needs to be encouraged in K-12 language classrooms. Lastly, there is a need for large scale systematic empirical assessment of technology uses to support language learning. Taking these into consideration, the question of CALL effectiveness, needs to be refined to examine how technology is being used, by whom, in what context and for what purpose [12]. As [39] acknowledges it is not the technology per se that can be classified as effective or ineffective, but the specific way in which the technology is used.

\subsection{Social Technologies in CALL}

Unlike the traditional Web 1.0, Web 2.0 changed the direction in communication on the internet [11]. With the reception of texts, sounds and images being the dominant activity, the readable Web 1.0 was followed by Web 2.0, the 'writable web', where the dominant activity is the creation of new content. Several studies indicate that these technologies provide fertile ground for collaboration, active participation, creative thinking, connectivity, and sharing of information and ideas among users, engaging learners in authentic, real-world situations and interactive communication [8], [10], [17], [24], [30]. Social collaboration in tagging and annotating documentation for navigation support is also highlighted by several studies, emphasizing the importance of social collaboration and its added value in learning environments [40-41].

Social software came into view as a major element of the Web 2.0 movement [2]. Prevalent software of this movement are blogs, wikis, podcasting, videoblogs, Myspace, Twitter and Facebook. These types of software differ significantly from static web-pages in the sense that they are open to the world and editable by everyone. Research conducted exploring the use of this software in the field of CALL focused on its effectiveness in supporting language learning, often in comparison with traditional instruction. For example, [3] studied the effects of blog-centered writing instruction vis-à-vis in class instruction on students' writing performance. The results indicated that learners who used blog software in their writing courses performed better than those who received only in class instruction in specific areas of writing, such as content and organization. In another study, [28] explored the development of meaningful interactions on a blog used by English as a Foreign Language (EFL) Master's students in France. The aim of this study was to measure the potential added value of a blog for the purpose of language learning, and more specifically for the development of learners' written expression. Findings demonstrated positive results in respect of participation and development of meaningful interactions, although the blog is not perceived as a "real life" one but a pedagogical one. Lee [14] provided a new insight into the practicality of implementing Web 2.0 tools in L2 teaching and learning. More specifically, this study explored the effectiveness of combined social networking applications, such as blogs and podcasts, for an intercultural communication and awareness between Spanish and American university students. The results of this study yielded that the use of blogs and podcasts offered promising benefits to both American and Spanish students who afforded unique opportunities to explore the 
target language and culture using digital technologies. On the same line, [15] explored the effectiveness of using a wiki for collaborative writing. The results indicated that wikis had a positive impact on students' writing through collaborative engagement. In another study, [16] reported on a study using blogs as out of class assignments for developing learners' language competence. The results showed that regular blogging impacts positively on learners' writing fluency and increases their motivation for writing for a broad audience. Moreover, peer feedback on the content incites further discussion, whereas feedback from the instructor on linguistic elements promotes focus on form for language accuracy. The study concluded by indicating two essential elements for the implementation of blog projects in L2 instruction, namely learners' critical thinking and technological skills. In another study, [6] also evaluated the usefulness of blogs for peer feedback on L2 writing. This study's findings demonstrated that blogs can be a valuable tool for peer feedback, however issues of students' and tutors' training as well as the aptness of tool against other learning technologies needs to be taken into consideration.

Furthermore, researchers explored how the features of Web 2.0 tools could be exploited so as to improve many aspects of traditional teaching. For example, a study that reports the experience of blog integration into an advanced Italian course by [18] showed that blogs not only offer a useful tool for practicing reading and writing skills, but can also promote learners' interaction and raise a sense of class community. For this to happen, however, careful attention to two key aspects is required: the way in which the use of the blog is integrated into the course content and structure, and the teachers' role in moderating and facilitating blog interaction.

Learners' interaction in a Web 2.0 environment is also under the microscope of research. Bradley, Lindström and Rystedt [5], for example, explored what interaction is developed in the wiki and how written interaction promotes language learning. Results revealed that there are different types of posted interaction among group members on the wiki. Students co-operate, namely they post individually on a common theme, but they also collaborate, they produce joint texts and then make alterations and additions. On the same line, [13] focused on collaborative construction of meaning among 40 Non Native Speakers (NNS) pre-service EFL teachers in a long-term wiki-based activity. Their results showed that students benefit from opportunities to practice autonomy in flexible learning environments. Their research also shed light on students' collaborative autonomous language learning abilities, and on the nature of students' individual and group behavior when attending to meaning. In another study, [33] turned to the use of voice blogs and explored them as a platform for an extensive study of language learners' speaking skills. The study demonstrated that a series of blogging stages were adopted by learners, including conceptualizing, brainstorming, articulation, monitoring and evaluation, as well as a series of strategies to cope with difficulties related to blogging. Additionally, learners did not only perceive blogs as a learning platform, but also as a means of self-presentation, information exchange and social networking. Finally, this study suggested blogging as a dynamic forum that enhances extensive practice, learning motivation, authorship and development of learning strategies [33].

Turning to the challenges faced in the use of wiki in the language classroom, [20] pointed out that the integration of wiki in the learning and teaching process does not necessarily guarantee learning outcomes, but the key to success are the well-designed 
activities blended into the curriculum. On the same line, [19] suggest further research to be conducted to identify the impact of ICT towards teaching and learning outcomes.

\subsection{Constructionism}

The present study draws on the theoretical framework of constructionism as it is developed by Seymour Papert [21-23]. Constructionism can be summarized in its evoking idea of learning-by-making [22]. Papert [22] unwraps his theory by highlighting its difference and similarity from Piaget's constructivism:

Constructionism--the $\mathrm{N}$ word as opposed to the $\mathrm{V}$ word--shares constructivism's connotation of learning as "building knowledge structures" irrespective of the circumstances of the learning. It then adds the idea that this happens especially felicitously in a context where the learner is consciously engaged in constructing a public entity, whether it's a sand castle on the beach or a theory of the universe [22]

Papert's theory can be summarized in his vision of a new educational environment in which learners build meaningful knowledge artifacts by taking advantage of the ubiquity of new technologies around them. The constructed artifact can be exposed, discussed, explored and admired, it is " in the world' -a sand castle or a cake, a Lego house or a corporation, a computer program, a poem, or a theory of the universe" [23]. Papert's [23] constructionism is based on the assumption that knowledge is gained when students find this knowledge for themselves and formal or informal education can promote knowledge attainment by providing moral, psychological, material and intellectual support. In addition to having students finding knowledge by themselves, Papert supports that computers are needed, as an environment through which rich activities can be developed, so called "microworlds".

Papert [23] sets as a main principle of constructionism the necessity for " objects to think with', objects in which there is an intersection of cultural presence, embedded knowledge and the possibility for personal identification" [23]. For Papert, a constructed computational object-to-think is a computer-controlled cybernetic animal (Turtle) within the LOGO computer language. Within the LOGO environment, the Turtle is an abstract object that can be made to move by giving commands. However, the role of Turtle is not to replace thinking but to enable learners to think with. In the environment of LOGO, programming is introduced when children experience programming by having the Turtle programmed to act in response to new commands [23].

The linkage between Distributed Constructionism and CALL has been established by [38] who explored the implementation of Distributed Constructionism through a Participatory Design methodology for an Online Learning Community. Throughout this study, the learners collaborated in developing the content of an online Modern Greek language course, peer reviewed and published content contributions, and participated in participatory design teams. In this study the Participatory Design was implemented as a four step process, namely: (a) build bridges with the intended users; (b) define user needs and recommendations to the system; (c) develop a prototype and (d) incorporate feedback and carry on the iteration. Additionally, Distributed Constructionism was employed to enhance the learning experience and community development. The findings revealed that Distributed Constructionism enhanced the 
learning experience of both the passive users and the Participatory Design team, whose contributions included replying to other students' language enquiries, helping out students to cope with technical problems and helping them explore resources to enhance their learning of the Greek language.

In another study, [29] provoke the need for a fundamental change in approaching teaching and learning. Thus, they attempt to contribute to the ongoing debate by presenting some key principles of constructivism as a new learner-centered paradigm for learning. Moreover, they consider Papert's constructionism as a basis for putting theory into practice for language learning, as a formula that could serve in the future "as the guiding principles for curriculum design, materials development, and classroom practice" [29]. Taking this as a stepping stone, the current study explores the applicability of Papert's theoretical framework in the use of social technologies in CALL.

\section{$3 \quad$ Setting}

This paper presents the results of a longitudinal inquiry of social technologies as social constructing platforms, in learning and teaching Greek as an L2. Social technologies were integrated in a one-year foundation course at a Greek speaking public university in the Republic of Cyprus. The course lasted for the academic year throughout September 2011 till May 2012. The class met face-to-face every day for five hours, in a total of 650 hours. In-class activities were held face-to-face and online, as well as out-door activities in order for students to practice the language in authentic, real-world situations. The course was particularly designed to meet the needs of university students who planned to study nursing. In the first semester, the language and content were drawn from students' experiences and other key learning areas such as nursing. In the second semester, the language and content were drawn exclusively from nursing. The course and the materials were tailored to meet the academic and professional needs of the nursing students.

All material related to the study was collected during an intensive 650-hour Greek language course at a newly established public university in Cyprus. The university accommodated approximately 2500 undergraduate and postgraduate students. The official language of the university is Greek. At the time of the research, $94 \%$ of the students attending the university were of Greek Cypriot ethnicity, $4.45 \%$ Greek, $0.3 \%$ Kenyan, $0.25 \%$ Ugandan, and the remaining $1 \%$ were made up of numerous other ethnicities, including British, Russian, Albanian, Bulgarian, Serbian, Iranian and Rumanian, according to university records.

\subsection{Students}

The participants in the intensive course were four male students from Kenya and Uganda, who came to Cyprus, for five years, on full scholarships. Students enrolled in the Greek course upon their arrival in Cyprus, had sessions every day for five hours. Despite the small sample, this study aimed to explore students' use of social technologies in depth. This study's horizon is to go in detail and in depth, despite the small sample, having participants work with social technologies in a long-term course, and collect data rich in detail about the use of social technologies. 
The students' age ranged from 19-23 years. All students were fluent English speakers; none of them had any knowledge of Greek upon arrival in Cyprus. Their computer skills were in general at basic to intermediate level. Three of them were able to turn the computer on and off; all of them had difficulties in advanced functions such as sending emails and attachments; document processing and use of keyboard. Additionally, they had minimal knowledge of social technologies, two of them created a Facebook account upon arrival to Cyprus, and none of them had any previous knowledge of blogs, wikis, Google documents or Dropbox.

\subsection{Instructor}

The instructor was a female, with four years experience in teaching Greek as an L2. The instructor was both participant and observer and her role provided access to as a wide-range of data as possible.

\subsection{Social Technologies}

Participants utilized five social technologies throughout the course: wikis, blogs, Facebook, Google documents, and Dropbox. The use of all technologies is explained in the following sections. The instructor set up two class wikis, Greek4Practice wiki and Lexicon wiki. Wikispaces was employed for creating the course wiki because of its simple, user-friendly interface that allows page layout to be easily changed. It is free and password-protected, easy to create and update. It uses open editing functionality and lets users create unlimited internal wiki pages and links. Users can also add other multimedia features including images, audio and video files to support the content. Wikispaces is currently available in many languages, including Greek, which enabled students to develop their site in the target language. Basic functions within the wiki include file or picture uploading, editing, creation of links and view of the history of pages. Wikispaces also allows its users to monitor the activity of the wiki and compare the differences between any two versions of the page.

The instructor created a Facebook group in which all participants were invited to join. Only members of the group were able to see the group information and content. Students were allowed to freely post anything of their interest on the Facebook group and make comments using the target language.

Following [4], the instructor set up one blog for the course, as it is more likely for classmates to interact with each other in one space. The blog allowed students to post and comment, upload material ant track the history of blog entries. For the instructor interface, the class blog tracked all posts and comments history.

Google documents were developed for sharing material related to the course. The instructor created and shared a folder of Google documents with students, who were allowed to view and edit. Google documents allows users to share, open and edit the document simultaneously. The Google service also enables users to view the revision history, additions made to a document, with each author distinguished by color.

Finally, all participants shared a Dropbox folder which included photos taken throughout the outdoor activities held. Dropbox enables all member of a shard folder to edit and re-post files. The version history is kept for 30 days. 


\section{Methodology}

The linkage between constructionism, social technologies and CALL and thereafter the generation of theory will emerge from the data collected throughout the intensive course of Greek described in the section above. This study's horizon is to go in detail and in depth, despite the small sample. Throughout the intensive Greek course, the students are involved with social construction of artifacts within social technologies, including wiki, Facebook, Blogger, Google Documents and Dropbox.

\subsection{Data Collection}

The data was collected using a variety of methods: a questionnaire, in class observations and daily field notes kept throughout the course by the researcher-instructor, instructors' and learners' weekly reflective diary kept on the wiki. Interviews were also conducted which allowed us to elicit qualitative data about the process that participants followed within social technologies. 16 interviews (4 per student) were conducted aiming at capturing students' overall impression and challenges of their learning process. A protocol was followed to explore students' opinions on overall experiences throughout the course. Each interview lasted approximately 45 minutes to one hour. The interviews were tape recorded and transcribed verbatim. Finally, students participated in a focus group which lasted approximately 30 minutes, and written notes were taken during the focus group. Table 1 briefly describes the types of data collected. To triangulate the findings, the study also collected data by observing students' activity within social technologies.

Table 1. Overview of Data Collected

\begin{tabular}{ll}
\hline Data & $\begin{array}{l}\text { Purpose } \\
\text { Questionnaire }\end{array}$ \\
Insight into students language and computer \\
literacy \\
Self evaluation of their activities outcomes \\
and process adopted \\
Reflection of activities outcomes \\
Instructors' reflections & $\begin{array}{l}\text { Overview of the process adopted and activi- } \\
\text { ties held } \\
\text { Instructors' field notes }\end{array}$ \\
Reflection on activity process and outcomes \\
Interviews & Overview of process adopted by the group \\
\hline
\end{tabular}

\subsection{Development of Code Scheme}

In order to become acquainted with the data, we first read all the data set thoroughly. This enabled us to acquaint a holistic view of the course development during analysis and take its context into account. Also, reading the course outline and profiles of the participants helped us to gather peripheral information about the course. Throughout this process, insights and ideas emerging from the data have been reported as memos within the Qualitative Research Software Nvivo. The purpose of this stage of analysis 
is "to ensure that the theoretical ideas which have emerged in the first round of coding can be systematically evidenced in the data, thus addressing the validity of the research results" [36].

In our code scheme, consecutive sentences that construct the same meaning are taken as one text unit and coded into a single code. This ensures that each coded segment captures the essence of described events in detail and it is still seen within its context [26]. The aim of this process is to classify and elucidate telling the story of the data [25]. A shortcoming of this approach is that the decision of what constitutes a meaning can be very subjective. To address this issue, we followed [26] approach, which developed a procedure as a guide for determining the unit of analysis. An intercoder reliability test with a sample of the data set revealed that two independent coders agreed on the segmentation in $81 \%$ of the cases.

In the second step, we analyzed the data set within the Qualitative Research Software Nvivo, extracting key words and themes observed. When we had a collection of themes and patterns that described the data, we sorted and grouped the codes and used them to develop the code scheme. Data was coded based on the target of an activity, for example when participants mentioned that they collected material from real situations in order to build their artifact within social technologies, we coded the segment under social technologies.

In the third step, we examined the code scheme by sensitizing concepts from Papert's theoretical framework [25]. This procedure was repeated iteratively, until a final code scheme was developed. Saturation was reached, when no new codes could be found and the data set could be sorted into the existing codes without any discrepancies. To make the code scheme as objective as possible, a codebook was developed, which clarified the description of the codes further. This codebook includes characteristics that distinguish the codes from each other and facilitates analysis process. To measure the inter-coder reliability, the codebook was given to another independent researcher who coded $10 \%$ of the data set. Cohen's KAPPA was calculated to be 0.72 which according to [32] is considered to be substantial.

\section{$5 \quad$ Results/Discussion}

Over the two semester course (26 weeks), the four participants and the instructor made a total of 1096 edits on the first wiki and 2086 edits on the second wiki. On average, each participant made 219 edits on the first wiki and 417 on the second wiki. On the Facebook Group the four participants and the instructor made 301 posts and 495 comments. On the blog a total of 26 posts and 40 comments were made and 1158 files were uploaded by the four participants and the instructor in the shared Dropbox folder.

\subsection{Social Technologies as Social Construction Platforms}

In this section the code scheme that manifests the use of social technologies as social construction platforms or as "objects-to-think with" is presented. Overall, three categories emerged: exploration of ideas, construction of artifact and evaluation of constructed artifact. 


\section{Exploration of ideas}

Orientation: Text units which refer to setting up the goals of an activity, providing objectives for a specific task (often the instructor challenges the students to identify why a specific activity takes place and how it should be formed).

Brainstorming: Text units which refer to making a list of ideas or content that could be used in the constructed artifact. Text units also refer to sharing notes and ideas within social network channels.

Material exploration: Text units which refer to exploration and collection of material by taking photos from real situations that learners experienced and by searching the web. The issue of cultural information exchange is prominent here since students often conducted activities out of class in order to collect material.

Construction of artifact

Outlining: Text units which refer to translating material from English to Greek, mapping the main and supporting ideas (before moving to putting the ideas down).

Editing material: Text units that refer to editing material, during the construction of the artifact. Editing material includes adding links and other multimedia material. Editing the material is rather a social than an individual task.

Evaluation of artifact

Revising: Text units which refer to the process in which the participant corrects production-errors. Spell check and automatic correctors are used. Revising is rather an iterative than an instantaneous process.

Peer reviewing: Text units which refer to peer reviewing the artifact in terms of organization, content and language usage. Comments were also employed for providing feedback within social technologies as a method for monitoring and evaluating a certain activity.

Instructor reviewing: Text units which refer to the instructor reviewing the constructed artifact in terms of organization, content and language usage.

Presenting/Publishing: Text units which refer to students presenting the constructed artifact to their classmates. Publication of the constructed artifact was done also via social communication channels (Facebook).

In the following sections we report the three dimensions that manifest social constructionism. We structure our discussion around the aforementioned dimensions, along with the actions occurring within each dimension that indicate the manifestation of constructionism within social technologies.

\subsection{Exploration of Ideas}

The first stage involved orientation towards the tool and the idea. In this stage, goals and objectives are set and the instructor often challenges the students to take preliminary decisions for exploring their and other's ideas. In the case of Papert's constructionism within the LOGO environment learners contact free with the learning environment; however in the case of applying constructionism within social technologies the exploration of ideas facilitated by the instructor is a vital step in the process. During this phase, the instructor introduces the tool to the learners through tutorials 
and step by step workshops. Students that participated in the course had difficulties in coping with the tools; however, the use of computer enabled them to enhance their language literacy:

Fred $4^{\text {th }}$ interview: When we started to work on wikispace writing, logging in and all those stuff I realized that it needs more practice because it is not easy as such. We need to go after links inside the wikispace and the good thing that I like in wikispace is that I realize that it helps a lot mostly when you write something in Greek.

Students need to explore a great deal before gaining mastery of how the technology works. However, the task is engaging and carries students through the learning process:

Nelson reflections: I really enjoyed this week, I learned how to put the voki in the lexicon, and I also learned a lot of things by adding new verbs in the link related to Nursing.

A major theme in constructionism is that the computer is seen as a "carrier of cultural 'germs' or 'seeds' whose intellectual products will not need technological support once they take root in an actively growing mind" [23]. Taking this a step forward, social constructionism assumes that learners can socially exchange "germs" or "seeds", throughout the brainstorming phase. In the framework of social constructionism, learners interact and exchange material throughout social communication channels. Facebook has been used as a tool for listing resources related to a specific topic. As it is shown in figure 1, an orientation task has been set by the instructor on Facebook requesting from students to search for material related to a specific topic. Participants have been listing related material by posting comments with material related to the specific topic.

The last action of this phase includes exploration of the material gathered, as well as out of class activities for photographing and collecting material in tasks that participants decided to include material from real situations.

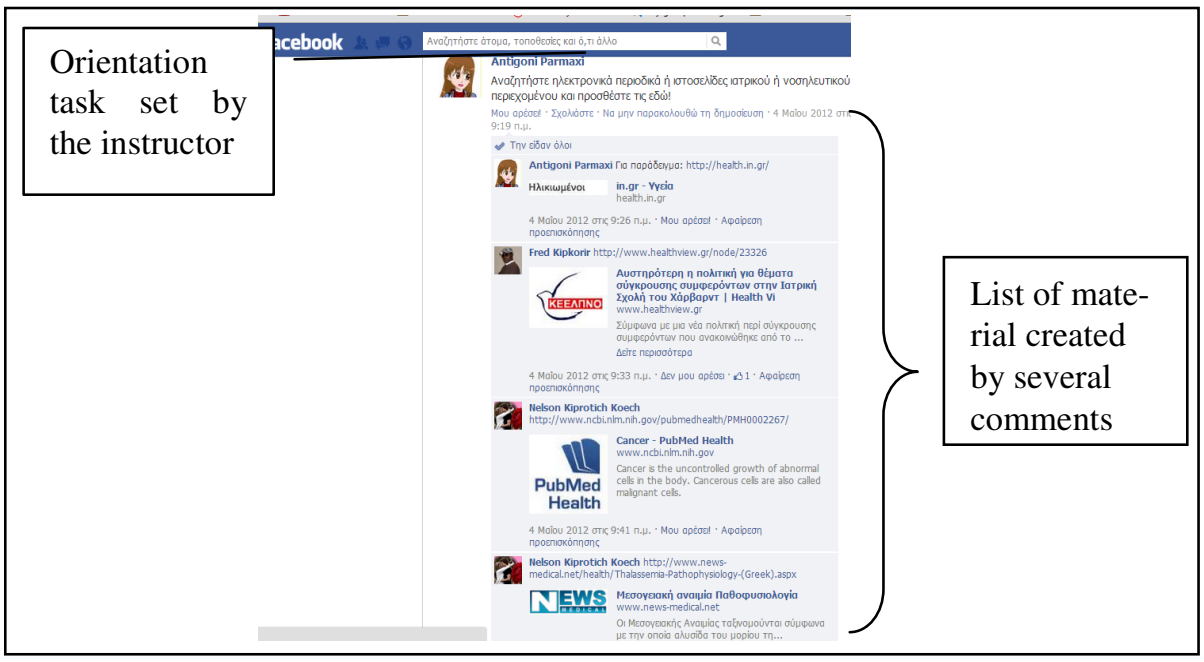

Fig. 1. Screenshot of social brainstorming in Facebook group 


\subsection{Construction of Artifact}

Learners begin their construction experience by translating material from English to Greek and mapping the main and supporting ideas:

Instructor's reflections: Students tried to read the material they found sentence by sentence and with the use of the translator to understand the basic information before start working on their own material.

Having the material understood, students move to more advanced commands. Students worked together in building an online dictionary which "can be shown, discussed examined, probed and admired" [23]. To this aim, during the exploration phase students focused in finding the topics that would be included and moved on in the construction phase, first by simple text editing and then by executing more complex actions such as picture uploading, adding plug-ins, videos, or other multimedia material (see fig. 2). Throughout this phase, learners are challenged to go through the artifact and enrich their computational and linguistic competences. The examples vary, but in each case learners practice in the use of language in a rich "object-to-think".

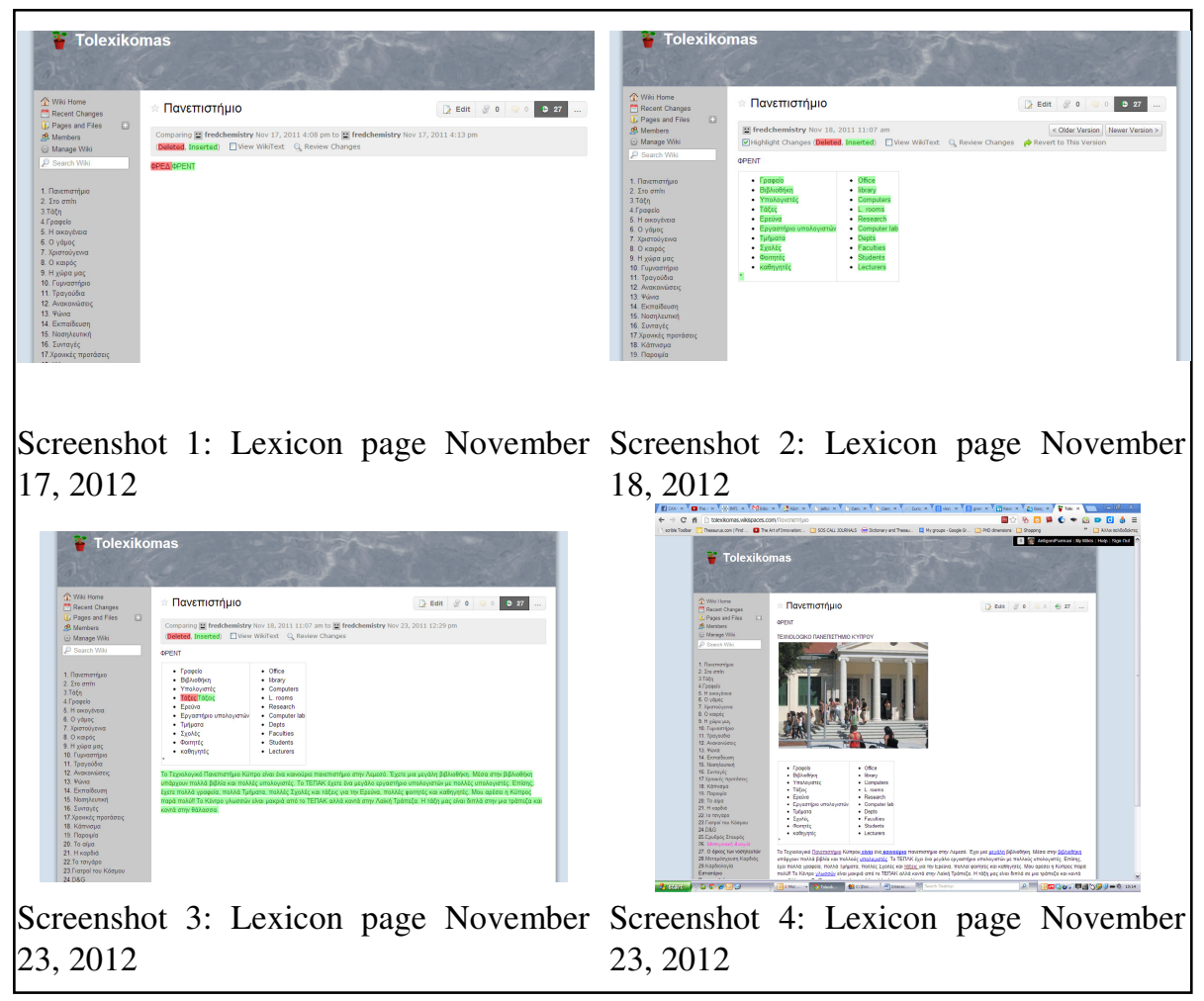

Fig. 2. Screenshots of the process of constructing the online dictionary 
Participants viewed this process of constructing the artifact as highly iterative and powerful since learners had to involve systematically in problem solving and explaining the constructed artifact to their potential audience:

Saul $3^{\text {rd }}$ interview: This procedure helps me because when you stick on doing something maybe you learn more. I have not been knowing how heart transplantation is called in Greek but I think I will not forget it, because when you look a certain word maybe once you can forget it easily but this one I will not forget it. I have just got it right now and many other words I have been working on.

\subsection{Evaluation of Artifact}

A central theme in constructionism is that "people seldom get anything exactly right on the first try" [23]. Within this framework, the construction of an artifact is seen as an iterative process that includes several modifications and revisions. The actions that participants followed in this stage include presentation of the constructed artifact to their peers either face to face or by publishing an artifact into social network channels. Participants during the presentation of their artifact receive feedback from their peers:

Saul reflections: In class I tried to do my best in presenting my work on the wiki and from the mistakes that I made I learned the correct.

Additionally, peers' and instructor's comments enable them to identify and correct their mistakes:

Siraj $4^{\text {th }}$ interview: In the blog we were discussing and exchanging views, so through those discussions we could see the mistakes of one another, written mistakes by reading through one another's posts.

Moreover, participants were monitoring the constructed artifact regularly, thus the evaluation of the artifact is seen as an iterative process. In the stage of revision, participants moved back and forth within the constructed artifact, making iterations in terms of organization of material, content and language usage:

Siraj interview: When I go to the Wikispaces I may write something wrong but after two or three weeks I go back and read through and I realize that I made a mistake. Maybe I did not know about that thing before and then I get to know. As I am passing through that text I see that I made a mistake and I correct it. And if I correct is not very easy to forget it.

Additionally, the instructor often challenged participants by highlighting their mistakes within the wiki or by providing comments in Facebook. As participants were reviewing what they have written they were challenged to think till they find the correct answer:

Instructor field notes: I tried to point out their mistakes on the wiki by highlighting incorrect sentences and also pointing out orally their mistakes.

In social constructionism environment, students are not criticized for errors but are rather encouraged to proceed on, and build on their mistakes. 


\subsection{Role(s) Adopted by Students and Instructor}

Instructor's role in the social constructionism framework can be marked as facilitator, supporter and reviewer. The instructor facilitates the orientation phase and reviews the constructed artifact. However, the instructor acts more as a member of the construction team rather than a judge. To this aim, the instructor supports students emotionally by giving advice and encouragement related to their progress:

Instructor's reflections: Remember that in every fight the first step is to believe in yourselves. What you have done so far proves your potentials.

Students act primarily as active constructors and reviewers of the artifact. Typically, in a language class the aim is to memorize as much information as possible, however in the social constructionism platform learners are encouraged to focus and understand their errors and involve in the process of correcting them.

\section{Conclusion and Future Work}

The current study explored social technologies from the perspective of constructionism. The three dimensions that emerged along with the respective actions that accompany each dimension reveal further dynamics of social technologies as social constructing platforms or in Papert terms "object-to-think". A social constructionism action model that takes into consideration the dynamics of social technologies could be represented in the triptych: exploration of ideas, construction and evaluation of artifact. This triptych captures the actions that take place throughout the social construction of an online artifact process. The learner is an energetic part of the whole process starting from exploration throughout the evaluation of the artifact. Peers and instructor are also involved in the process in multiple actions. The instructor acts as facilitator in orienting the ideas in the exploration phase; supporter for participants in the construction phase and reviewer in the evaluation phase. Peers are involved in coforming decisions in the whole process. Social technologies are an integral part of the process; however the essence of social constructionism lies in the artifact itself that produces understanding through construction of an explicit representation.

In our view these actions provide a view of different aspects of how the construction of an online artifact manifests in practice. From the perspective of knowledge creation, the construction of an online artifact within social technologies allows learners to think and understand abstract scenarios by linking them with a tangible artifact. From the perspective of design, this paper views constructionism as a fertile ground for learners to experience the design of an online artifact not as learners but as designers and researchers. Although we frame social constructionism within the limits of CALL, we believe that the emergent dimensions can serve future efforts to support learning, collaboration and problem solving.

The results of this study reveal that social constructionism demands a series of actions, including orientation, brainstorming, material exploration, outlining, editing material, revising, instructor reviewing, peer reviewing and presenting. These actions are expected to supply designers, instructors, researchers and practitioners with a better understanding of the affordances of social technologies, leading to a new perspective of their use. 
We encourage future research to explore the validity and applicability of our code scheme in areas other than language. Moreover, an overall framework needs to be developed that will reveal theoretical and methodological aspects of social constructionism. Taking into consideration the intertwined relationship between language and culture, further research will be conducted exploring whether cultural scenarios can provide an exemplary framework through which social constructionism can be implemented. Finally, we seek for further studies that explore the components of constructionism in other environments and learning subjects, online or offline, which could result in its wider applicability as a means for enhancing knowledge.

Future research could be conducted in applying social constructionism in social and $3 \mathrm{D}$ environments as well as mobile applications in order for learners to construct their "objects-to-think". The framework and the actions that are described in this study may also inform several stages of research in HCI, enabling the analysis, design, development and evaluation process within a social environment following the aforementioned actions of social constructionism. Moreover, the actions that take place throughout social constructionism could inform designers to refine the development of social platforms so as to facilitate the construction of online artifacts.

From the perspective of practitioners, social constructionism can inform curriculum design, materials development and classroom praxis. Research on the possible contributions of social technologies as social construction platforms is still in its infancy. More research on different artifact types and different subjects could clarify aspects of constructionism and help create better pedagogical approaches for various instructional purposes.

Acknowledgements. We would like to thank Fred Kipkorir, Nelson Kiprotich, Mutyaba Saul and Sirajdin Ssemugenyi for their support and invaluable contribution for conducting this study.

\section{References}

1. Abraham, L.B.: Computer-mediated glosses in second language reading comprehension and vocabulary learning: A meta-analysis. Computer Assisted Language Learning 21(3), 199-226 (2008)

2. Alexander, B.: Web 2.0: A New Wave of Innovation for Teaching. Educause Review 41(2), 32-44 (2006)

3. Arslan, R.Ş., Şahin-Kızıl, A.: How can the use of blog software facilitate the writing process of English language learners? Computer Assisted Language Learning 23(3), 183-197 (2010)

4. Bloch, J.: Abdullah's blogging: A generation 1.5 student enters the blogosphere. Language Learning \& Technology 11(2), 128-141 (2007)

5. Bradley, L., Lindström, B., Rystedt, H.: Rationalities of collaboration for language learning in a wiki. ReCALL 22(2), 247-265 (2010)

6. Dippold, D.: Peer feedback through blogs: student and teacher perceptions in an advanced German class. ReCALL 21(1), 18-36 (2009)

7. Gamper, J., Knapp, J.: A review of Intelligent CALL systems. Computer Assisted Language Learning 15(4), 329-342 (2002) 
8. Glassman, M., Kang, M.J.: The logic of wikis: The possibilities of the Web 2.0 classroom. The International Journal of Computer-Supported Collaborative Learning 6(1), 93-112 (2011)

9. Goldberg, A., Russell, M., Cook, A.: The effect of computers on student writing: A metaanalysis of studies from 1992-2002. Journal of Technology, Learning and Assessment 2(1) (2003)

10. Ioannou, A.: Collaborative Learning: The Promise of Wikis. Word Journal of the International Linguistic Association 38(3), 213-224 (2011)

11. Kárpáti, A.: Web 2 technologies for Net Native language learners: A "social CALL". ReCALL 21(2), 139-156 (2009)

12. Kern, R.: Perspectives on technology in learning and teaching languages. TESOL Quarterly 40, 183-210 (2006)

13. Kessler, G., Bikowski, D.: Developing collaborative autonomous learning abilities in computer mediated language learning: attention to meaning among students in wiki space. Computer Assisted Language Learning 23(1), 41-58 (2010)

14. Lee, L.: Promoting intercultural exchanges with blogs and podcasting: a study of SpanishAmerican telecollaboration. Computer Assisted Language Learning 22(5), 425-443 (2009)

15. Lee, L.: Exploring wiki-mediated collaborative writing: a case study in an elementary Spanish course. CALICO Journal 27(2), 260-276 (2010)

16. Lee, L.: Fostering reflective writing and interactive exchange through blogging in an advanced language course. ReCALL 22(2), 212-227 (2010)

17. McLoughlin, C., Lee, M.J.W.: Social software and participatory learning: Pedagogical choices with technology affordances in the Web 2.0 era. In: Atkinson, R.J., McBeath, C., Soong, S.K.A., Cheers, C. (eds.) ICT Providing Choices for Learners and Learning Proceedings Ascilite Singapore 2007, vol. 2007, pp. 664-675. Ascilite Singapore (2007), http: / /www.ascilite.org.au/conferences/singapore07/procs / mcloughlin.pdf (retrieved)

18. Miceli, T., Murray, S.V., Kennedy, C.: Using an L2 blog to enhance learners' participation and sense of community. Computer Assisted Language Learning 23(4), 321-341 (2010)

19. Nisiforou, E., Laghos, A.: An Overview: The Development of ICT in the Educational System of Cyprus. In: Global Learn Asia Pacific, vol. 2011(1), pp. 534-539 (2011)

20. Papadima-Sophocleous, P., Parmaxi, A.: The use of wiki in teaching and learning Greek as a second language for specific academic purposes: challenges and future perspectives. In: Buston, J., Tsagari, D., Doa, F. (eds.) Foreign Language Instructional Technology: Theory \& Practice, pp. 128-139. University of Nicosia Press, Nicosia (2012)

21. Papert, S.: Mindstorms: Children, Computers and Powerful Ideas. Basic Books, New York (1980)

22. Papert, S., Harel, I.: Situating Constructionism. In: Papert, S., Harel, I. (eds.) Constructionism, vol. 36, pp. 1-11. Ablex Publishing (1991)

23. Papert, S.: The Children's Machine: Rethinking School in the Age of the Computer. Basic Books, New York (1993)

24. Parker, K.R., Chao, J.T.: Wiki as a Teaching Tool. Learning 3(3), 57-72 (2007)

25. Patton, M.Q.: Qualitative research \& evaluation methods. Sage Publications, Incorporated (2002)

26. Pfeil, U., Zaphiris, P.: Patterns of empathy in online communication. In: Proceedings of the SIGCHI Conference on Human Factors in Computing Systems, CHI 2007, pp. 919-928. ACM Press (2007)

27. QSR International. Nvivo 10 qualitative research software 
28. Rivens Mompean, A.: The development of meaningful interactions on a blog used for the learning of English as a Foreign Language. ReCALL 22(3), 376-395 (2010)

29. Ruschoff, B., Ritter, M.: Technology-Enhanced Language Learning: Construction of Knowledge and Template-Based Learning in the Foreign Language Classroom. Computer Assisted Language Learning 14(3-4), 219-232 (2001)

30. Seitzinger, J.: Be Constructive: Blogs, Podcasts, and Wikis as Constructivist Learning Tools. Learning Solutions eMagazine, 1-16 (July 31, 2006),

http://citeseerx.ist.psu.edu/viewdoc/

download?doi=10.1.1.121.4071\&rep=rep1\&type=pdf (retrieved)

31. Smith, P.L., Ragan, T.J.: Instructional design, 3rd edn. Wiley, New York (2005)

32. Stemler, S.: An overview of content analysis. Practical Assessment Research Evaluation 7(17), 479-498 (2001)

33. Sun, Y.C.: Voice blog: an exploratory study of language learning. Language Learning and Technology 13(2), 88-103 (2009)

34. Taylor, A.M.: The effects of CALL versus traditional L1 glosses on L2 reading comprehension. CALICO Journal 23(2), 309-318 (2006)

35. Taylor, A.M.: CALL-based versus Paper-based glosses: Is there a difference in reading comprehension? CALICO Journal 27(1), 147-160 (2009)

36. Welsh, E.: Dealing with Data: Using NVivo in the Qualitative Data Analysis Process 1. Approaches to Qualitative Data Analysis 3(2), 1-7 (2002)

37. Yun, J.: The effects of hypertext glosses on L2 vocabulary acquisition: A meta-analysis. Computer Assisted Language Learning 24(1), 39-58 (2011)

38. Zaphiris, P., Zacharia, G., Rajasekaran, M.: Distributed Constructionism through Participatory Design. Group, pp. 164-179 (2003), http: / / books . google.com/

books ?hl=en\&lr=\&id=GaUGj cpjo7AC\&Oi=fnd\&pg=PA164\&dq=Distribut ed+Constructionism+through+Participatory+Design\&ots=nr3a7UZe s7\&sig=Mwum2xiy41oDbi $2 \times 4$ zrRUe-0Z8M (retrieved)

39. Zhao, Y.: Recent development in technology and language learning: A literature review and meta-analysis. CALICO Journal 21(1), 7-27 (2003)

40. Bateman, S., Farzan, R., Brusilovsky, P., Mccalla, G.: OATS: The Open Annotation and Tagging System. Information Sciences (2006), http: / scholar.google.com/ scholar?hl=en\&q=OATS+the+open+annotation+and+tagging+ system\&btnG=Search\#0 (retrieved)

41. Bateman, S., Brooks, C., McCalla, G., Brusilovsky, P.: Applying Collaborative Tagging to E-Learning. Human Factors 3(4), 1-7 (2007), http : / / citeseerx. ist.psu . edu / viewdoc / download?doi=10.1.1.64.8892\&rep=rep1\&type=pdf (retrieved) 